\title{
Aerobic and concentration training and allele 7 in the dopamine receptor D4 (D4DR) gene increase chances of smoking cessation in young Polish women
}

Tomasz Podgórski¹, Grażyna Szmyt², Agnieszka Szmyt² , Joanna Gronek³ ${ }^{3}$ Roman Celka ${ }^{3}$, Piotr Gronek ${ }^{4}$

\author{
${ }^{1}$ Department of Biochemistry, Poznan University of Physical Education, Poznan, \\ Poland \\ ${ }^{2}$ Cosmetology, College of Health, Beauty and Education, Poznan, Poland \\ ${ }^{3}$ Department of Gymnastics, Poznan University of Physical Education, Poznan, Poland \\ ${ }^{4}$ Department of Dance Sciences, Poznan University of Physical Education, Poznan, \\ Poland
}

Submitted: 21 December 2016

Accepted: 29 March 2017

Arch Med Sci 2018; 14, 1: 199-206

DOI: https://doi.org/10.5114/aoms.2018.72243

Copyright $\odot 2017$ Termedia \& Banach

\begin{abstract}
Introduction: One reason for the limited effectiveness of the available smoking cessation methods is the fact that the causes of tobacco addiction have not been adequately explained yet. Numerous anti-smoking programs aimed at women involve intense physical activity. The goal of the study was to evaluate the effectiveness of health training for smoking cessation by young women in connection with the dopamine receptor gene $(D 4 D R)$ in their genetic profile.

Material and methods: Forty-eight adult female smokers were randomly assigned to: 1) a concentration training group, or 2) an aerobic and concentration training group. Genetic and phenotypic data were obtained from 48 participants. Genotyping was performed for allele 7 in the D4DR gene.

Results: Individuals with allele 7 in the dopamine receptor D4 gene have two times greater chances $(\mathrm{OR}=2.13: 95 \% \mathrm{Cl}$ : 0.91-4.96) of quitting smoking than individuals without allele 7 . No statistical significance was revealed $(p=0.0805)$. Individuals undertaking aerobic training in combination with concentration training are three times more likely $(\mathrm{OR}=3.06: 95 \% \mathrm{Cl}: 1.03-$ $9.05)$ to quit smoking than individuals who do not perform aerobic training $(p=0.0439)$.

Conclusions: The results of the study show that an intensive, 6-week health training program had a significant influence on smoking cessation. Smoking quitters, who are genetically predisposed and decide to take up aerobic training in combination with concentration training, have much greater chances of quitting smoking.
\end{abstract}

Key words: smoking cessation, aerobic training, concentration training, $D 4 D R$ receptor gene.

\section{Introduction}

It is estimated that among 1.3 billion people addicted to nicotine, about $70 \%$ are determined to kick the habit with the aid of one of the available smoking cessation methods [1-3]. One reason for the limited effectiveness of the available smoking cessation methods is the fact that the causes of tobacco addiction have not been adequately explained yet [4]. An-

\author{
Corresponding author: \\ Tomasz Podgórski \\ Department of \\ Biochemistry \\ Poznan University \\ of Physical Education \\ 27/39 Królowej Jadwigi St \\ 61-871 Poznan, Poland \\ Phone: +48 618355181 \\ Fax: +48 618355188 \\ E-mail: podgorski@awf. \\ poznan.pl
}


other factor contributing to unsuccessful smoking cessation is modern fast life involving high levels of stress, insufficient relaxation time, poorly balanced diet, and limited physical activity $[5,6]$. There has been a significant difference in the pattern of nicotine addiction between men and women [7]. The numerous anti-smoking programs addressed to women involve intense physical activity [8, 9].

Nicotine addiction may be genetically determined [10], and one of the candidate genes may be the dopamine receptor gene $(D 4 D R)$ [11]. Although $D 4 D R$ is predominantly correlated with opioid dependence, its association with nicotine dependence must not be excluded. Interestingly, the $D 4 D R$ gene is also associated with novelty seeking dependence, as one of the D4DR alleles was observed in extreme parachuters and climbers [10]. $D 4 D R$ is thought to affect exploring and extravert behaviors, which may be connected with positive emotions involved in novelty seeking (neophilia).

The present study sought to find genetic determinants of successful smoking cessation. The study considered the genotype of the D4DR receptor gene, which had been found to be correlated opioid dependence $[10,11]$. The present study assumed that there might be a relationship between the D4DR gene and tobacco addiction and successful smoking cessation.

\section{Material and methods}

\section{Ethics committee}

The ethical committee of the Poznan University of Medical Sciences approved the study (Bioethics Committee of the Poznan University of Medical Sciences, no. 534/12 from May 10, 2012). The study complied with the guidelines set out in the Declaration of Helsinki and the ethics policy of the University School of Physical Education, Poznan.

\section{Subject recruitment}

The study sample comprised 287 female fulltime undergraduate students of cosmetology from the College of Health, Beauty and Education in Poznan, Poland. The participants' mean age was $21 \pm 1.68$ years. Among 118 female students who were smokers, only 79 (67\%) expressed a wish to kick the habit, and 57 (72\%) of them intended to take part in the offered health training program for smoking cessation. Ultimately, 48 smoking students who fulfilled the selection criteria were randomly divided into two groups and took part in the study. Group $1(n=22)$ consisted of students undertaking concentration training only. Group 2 $(n=26)$ comprised students undertaking aerobic training and concentration training. Students in each group underwent 6-week individually adjusted training sessions.

\section{Detailed anthropometric assessment}

Before and after completion of the training program, basic anthropometric measurements of body height, body mass and body mass index (BMI) were taken from all the students.

The analysis of changes in body mass revealed that the 6-week training had a significant impact on $\mathrm{BMI}$ reduction ( $p=0.0088$ ) among the group 2 students participating in aerobic exercises. Among the students of group 1 undertaking concentration training only, the $\mathrm{BMI}$ remained unchanged, and the differences were statistically non-significant $(p=0.9987)$.

\section{Concentration training}

Women in both study groups performed concentration exercises, which were based on training programs for high-performance athletes [12-14]. Their concentration times were measured twice: before the study and after its completion, with a stopwatch, from the beginning of exercise until committing the first error, which in accordance with the accepted research methodology was treated as a sign of lack of concentration.

The participants were instructed about the correct execution of concentration exercises so they could perform them on their own, from 7 a.m. to 7 p.m., or 9 a.m. to 9 p.m., for 5 min, every $2 \mathrm{~h}$. The women from both study groups met twice a week for a joint 60-min concentration training session.

\section{Aerobic training}

The participants from group 2 were supposed to choose five of eight proposals of aerobics classes, depending on their interests, preferences, and time. A class lasted from 60 to $75 \mathrm{~min}$, while a swimming class lasted $45 \mathrm{~min}$.

The weekly training schedule was as follows:

- Monday: swimming and general fitness training (low-impact aerobics, total body condition (TBC), OVOball),

- Tuesday: Hi/Lo aerobic dance, ABT (abdominal, buttocks, thighs),

- Wednesday: Pilates or Fit ball,

- Thursday: Zumba,

- Friday: body posture exercises,

- Saturday: jogging or Nordic walking,

- Sunday: cycling or Nordic walking.

The training loads were calculated according to the formula by Miller et al. [15]. The exercises were performed by participants in the same age range (Table I), but at different physical fitness levels. Due to individual differences in exercise tolerance between the participants the instructor chose training loads individually in each class. All participants were informed about movement 
Table I. Anthropometric characteristics of participants. Baseline mean values of age, body mass, body height and $\mathrm{BMI}$ in women from group 1 and group 2

\begin{tabular}{|lccc|}
\hline Variable & Group $1(n=22)$ & Group $2(n=26)$ & $P$-value \\
& $\bar{x} \pm$ SD (min.; max.) & $\bar{x} \pm$ SD (min.; max.) & \\
\hline Age [years] & $20.8 \pm 1.97$ & $20.4 \pm 1.20$ & 0.374 \\
& $(19 ; 25)$ & $(19 ; 24)$ & 0.227 \\
\hline Body mass [kg] & $62.3 \pm 9.72$ & $59.4 \pm 6.04$ & \\
& $(46 ; 87)$ & $(51 ; 79)$ & 0.918 \\
\hline Body height $[\mathrm{m}]$ & $166.5 \pm 4.94$ & $(156.6 \pm 5.78$ & \\
& $(158 ; 174)$ & $21.7 \pm 1.85$ & 0.201 \\
\hline BMI $\left[\mathrm{kg} / \mathrm{m}^{2}\right]$ & $22.5 \pm 3.43$ & $(17.94 ; 26.70)$ & \\
& $(17.53 ; 32.03)$ & &
\end{tabular}

intensity and chose their physical activities consciously and more effectively.

\section{Genotyping}

The buccal cells donated by the subjects were collected in Resuspension Solution (Sigma, Germany) using Sterile Foam Tipped Applicators (Puritan, USA). DNA was extracted from the buccal cells using GenElute Mammalian Genomic DNA Miniprep Kit (Sigma, Germany) according to the producer protocol. Forty-eight Caucasian women were recruited to this study.

\section{D4DR genotyping}

PCR amplification used the forward primer: 5'-GCGACTACGTGCTACTCG-3', and the reversed primer: 5'-AGGACCCTCATGGCCTTG-3' as recommended by Benjamin et al. [11]. $12.5 \mu \mathrm{l}$ of reaction mixture contained $1 \times$ Vent buffer (New England Biolabs), $1 \mu \mathrm{M}$ primers, $62.5 \mathrm{ng}$ of genome DNA, $400 \mu \mathrm{M}$ DTP and $0.25 \mathrm{U}$ of DNA polymerase. The PCR was carried out in thirty cycles. The PCR products were separated using nucleic acid electrophoresis in 2\% MetaPhor gel (FMC) stained with ethidium bromide.

\section{Statistical analysis}

The statistical significance of differences between the mean values in the compared groups of participants and terms of measurement was checked with properly chosen statistical tests. The use of parametric tests was determined by the presence of normal distribution of the variables and homogeneity of variance. For all quantitative parameters the conformity of their distribution was checked against a normal distribution with the Shapiro-Wilk test, and the equality of variances was checked with Levene's test.

The significance of mean differences between two terms of measurement in both groups was assessed with an analysis of variance with repeated measures. Tukey's HSD test was used to verify the differences. The Wilcoxon test was used to assess the significance of mean differences, concentration time, aerobic training time, and BMI in the entire study sample between two terms of measurement. The chances of quitting smoking were assessed with single-factor and multi-factor logistic regression analysis. All calculations were made using the Statistica 10.0 software package (StatSoft. Inc., USA).

\section{Results}

\section{D4DR genotyping}

The present study assessed whether the presence of allele 4 or 7 in the $D 4 D R$ gene affects the level of probability of smoking cessation. The distribution of the alleles in 48 participants was as follows: allele 7 absent $(n=24)$, allele 7 present $(n=24)$. As for the nine participants who quit smoking in the last week of the study, the distribution of alleles was: allele 7 present $(n=7)$; allele 7 absent $(n=2)$ (Figure 1$)$. A tendency toward statistical significance of smoking cessation chances was noted in participants with allele 7 in the $D 4 D R$ gene.

The results of a single-factor logistic regression analysis (Figures 2-4) revealed the determinants of smoking cessation. The dependent variable in

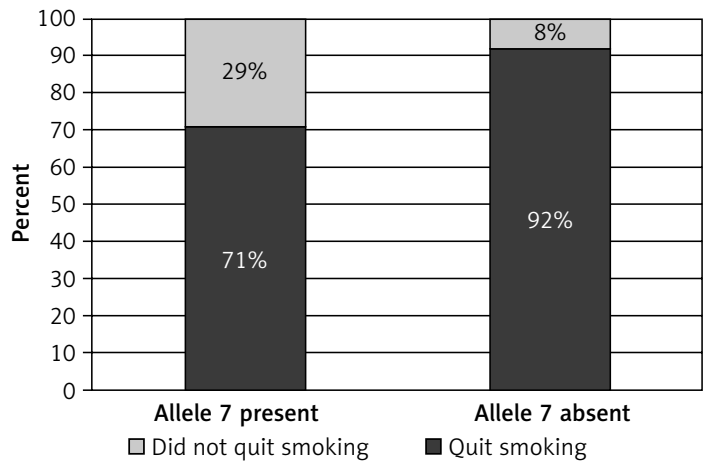

Figure 1. Percent distribution of participants who quit and did not quit smoking, depending on the presence of allele 7 in the study sample $(n=48)$. No statistical significance was found between the genotype and chance of smoking cessation (Pearson's $\chi^{2}$ test, $p=0.0645$ ) 


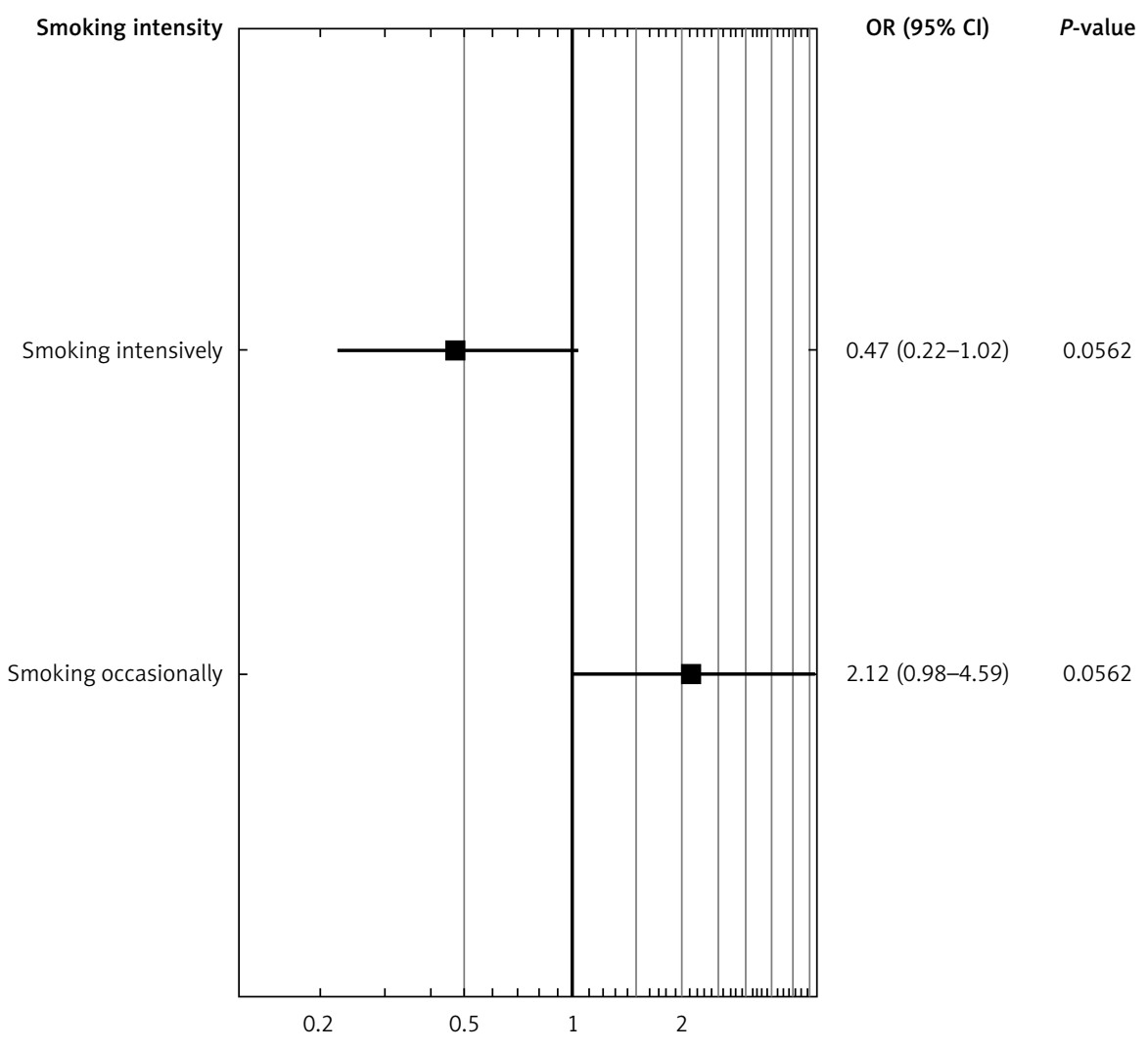

Figure 2. Single-factor logistic regression analysis between smoking cessation and smoking intensity

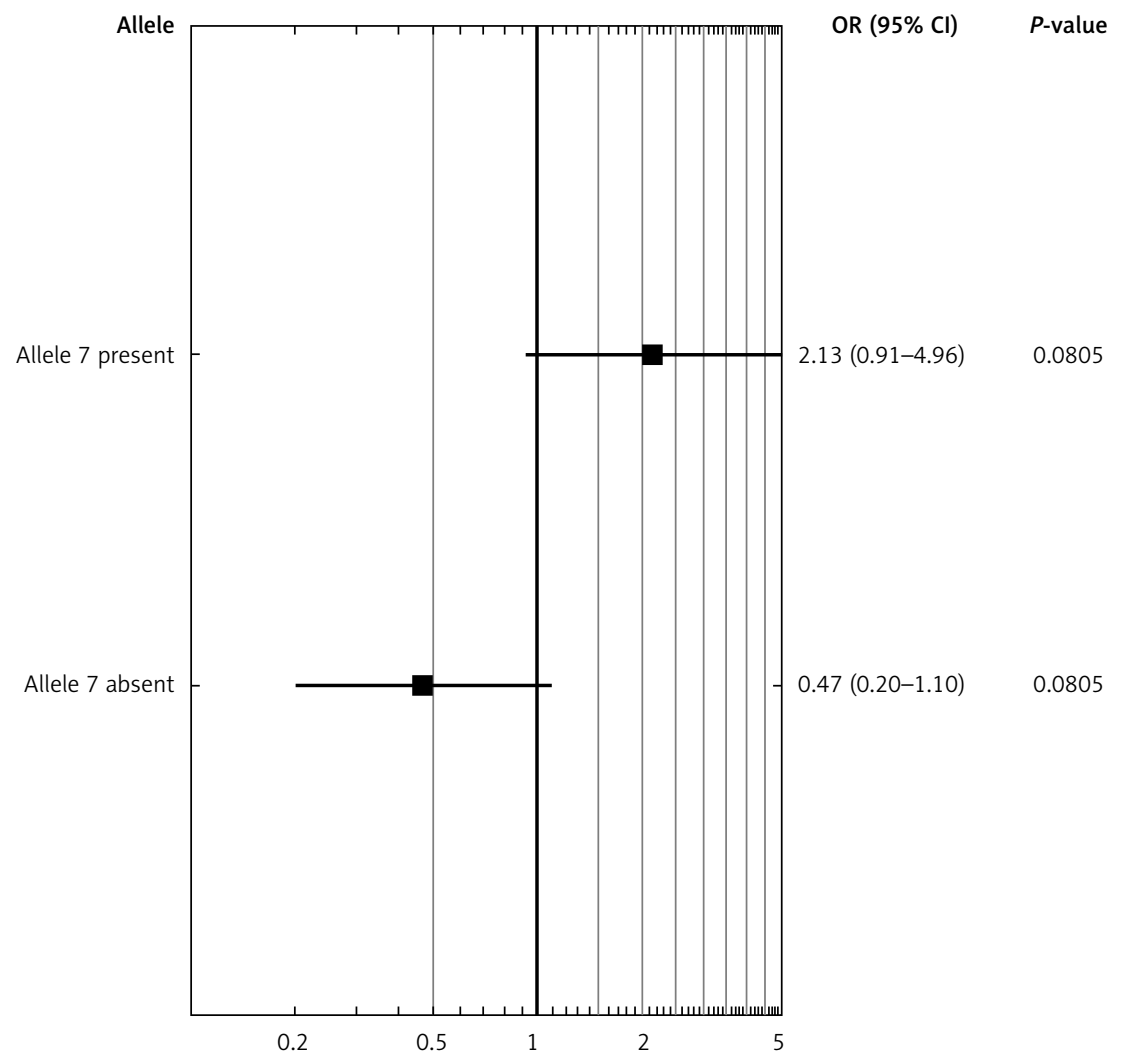

Figure 3. Single-factor logistic regression analysis between genotype and smoking cessation 


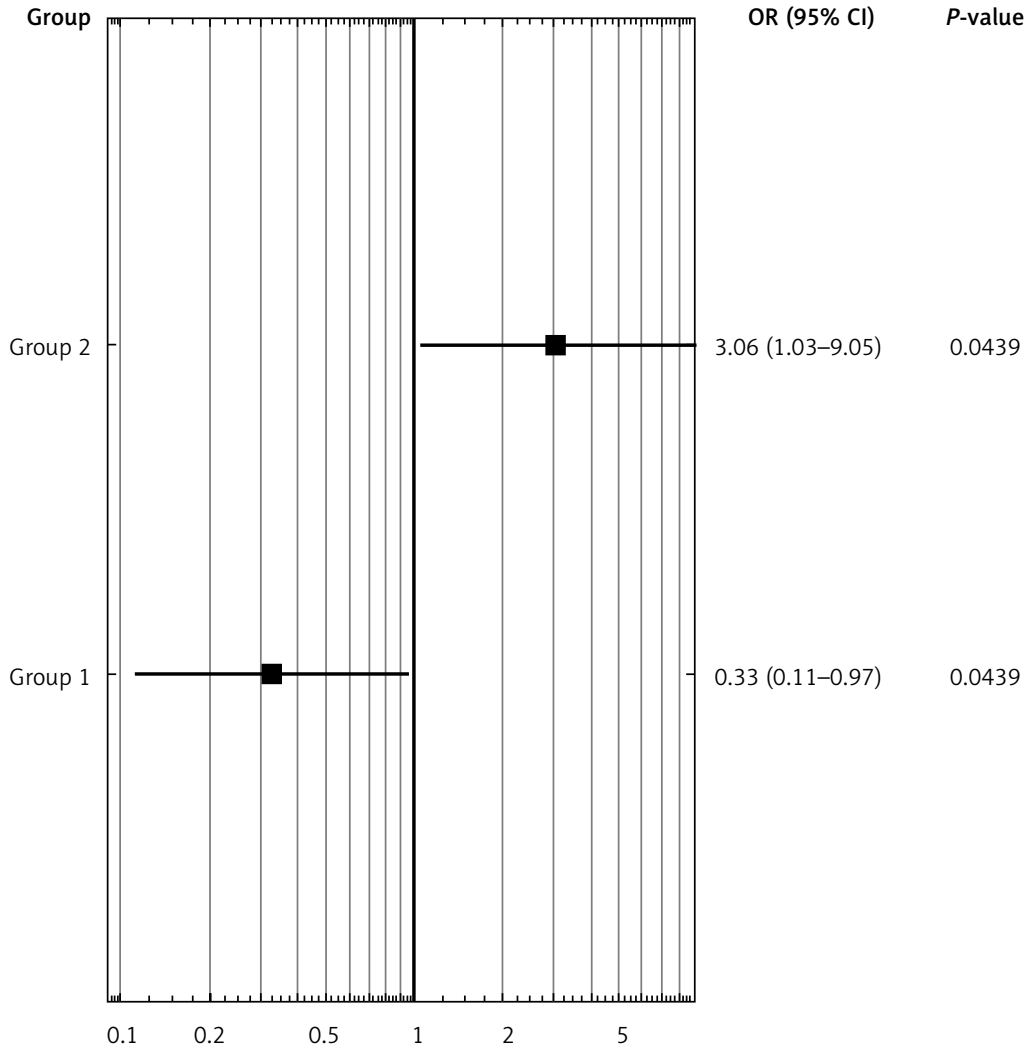

Figure 4. Single-factor logistic regression analysis between study group type and smoking cessation

the model was smoking cessation as a dichotomous variable with two groups: 1 - not smoking, 0 - smoking. The independent variables were smoking intensity, study group and allele. In the present study the study sample was divided into three groups with regard to the number of smoked cigarettes a day:

- under 5 cigarettes a day - smoking occasionally - over 5 cigarettes a day - smoking intensively

and in terms of the length of tobacco dependence (years of addiction) into:

- under 3 years - smoking for a short time

- over 3 years - smoking for a long time.

The relationship between different values of factors and smoking cessation was presented as the odds ratio (OR) and 95\% confidence interval $(95 \% \mathrm{Cl})$ between smokers and non-smokers.

Table II shows the $p$-values of the likelihood ration (LR) test based on a comparison of the maximal values of likelihood ratio between two models: the present model and the reference model, with the former being an initial test of model significance.

\section{Smoking intensity}

The single-factor logistic regression analysis between smoking cessation and smoking intensity revealed that individuals who smoked cigarettes occasionally are twice as likely to quit smoking $(\mathrm{OR}=2.12 ; 95 \% \mathrm{Cl}: 0.98-4.59 ; p=0.0562)$ (Figure 2).

\section{D4DR gene}

The single-factor logistic regression analysis between allele presence and smoking cessation and smoking intensity showed that individuals with allele 7 are twice as likely to quit smoking $(\mathrm{OR}=2.13: 95 \% \mathrm{Cl}: 0.91-4.96 ; p=0.0805)$ than individuals without allele 7 (Figure 3 ).

\section{Study groups}

The single-factor logistic regression analysis carried out between the study group type and smoking cessation showed that the participants undertaking aerobic training in combination with concentration training (group 2) are three times more likely to quit smoking $(\mathrm{OR}=3.06: 95 \% \mathrm{Cl}$ : 1.03-9.05) than participants who did not perform aerobic training ( $p=0.0439)$ (Figure 4$)$.

The results of the analysis were used to design a multi-factor logistic regression model which included such variables as smoking intensity, study

Table II. Maximal values of likelihood ratio of the present model and the reference model

\begin{tabular}{|lc|}
\hline Model parameters & $P$-value (LR) \\
\hline Smoking intensity & 0.0481 \\
\hline Allele 7 present & 0.0583 \\
\hline Group 2 & 0.0136 \\
\hline
\end{tabular}


Table III. Parameters of multi-factor logistic regression models

\begin{tabular}{|lccccc|}
\hline Parameter & Level - effect & Estimate & $P$-value & OR & $95 \% \mathrm{Cl}$ \\
\hline Allele & Allele 7 present & 0.86 & 0.061 & 2.35 & $0.96-5.77$ \\
\hline Group & Group 2 & 1.15 & 0.043 & 3.17 & $1.04-9.70$ \\
\hline
\end{tabular}

group, and allele presence. All the variables in the model were significant predictors of smoking cessation. The positive estimates of the parameters corresponding to the variables allele presence and group showed that in participants with allele 7 and participants from group 2 the likelihood of smoking cessation increases. The greatest increase was found for the variable group. The odds ratio for the variable group (3.17) indicated that the likelihood of smoking cessation for participants from group 2 was more than three times greater than for participants from group 1. Similarly, for the variable allele presence the odds ratio of 2.35 pointed to two times greater likelihood of smoking cessation in participants with allele 7 than in participants without allele 7 (Table III).

\section{Discussion}

Darlow and Lobel [4] reported that $70 \%$ of individuals addicted to nicotine are determined to quit the habit using one of the available smoking cessation methods [16-18]. Different forms of nicotine replacement therapy lead to effective smoking cessation only in one out of 5 smokers [19]. The results of the present study appear to confirm this observation.

Young women often claim that they smoke to look slim and attractive [20, 21]. In fact, all antismoking programs for women should account for women's physical attractiveness and their concern with possible body mass increase after smoking cessation [21, 22].

It is estimated that body mass may increase by $5-6 \%$, i.e. by $8-10 \mathrm{~kg}$, after quitting smoking [23, $24]$. The fear of getting fat is often a discouragement to young people to quit smoking. If women begin quitting smoking and are initially successful, an increase in their body mass may often result in returning to the habit [25].

It may be concluded that smoking quitters who perform training exercises of appropriate volume and intensity do not have to be concerned over body weight. It can be assumed that the differences in body weight in the participants of the present study, between the first term of measurement (before the study) and the second term (after the study), did not result from the greater body fat in the women, but from bigger training-enhanced muscles.

In the present study, aerobic training played a significant role in group 2 girls' motivation to quit smoking, as shown by the single-factor logistic regression analysis ( $\mathrm{OR}=3.06: 95 \% \mathrm{Cl}: 1.03-9.05)$.

The obtained results show that physical activity and aerobic training may have a significant influence on smoking cessation attempts, as indicated by the logistic regression analysis of the relationship between smoking cessation and other variables. Similar observations were made by Ciccolo et al. [26], and the results confirm the assertion of those authors who claim that physical exercise is crucial for smoking quitters and is positively correlated with a decrease in the number of cigarettes smoked daily [26]. Physical activity is conducive to and enhances the chances of smoking cessation. Williams et al. [27] and Gimenez et al. [28] observed positive effects of aerobic training consisting of climbing double steps (15 cm high) at the incremental intensity of $10,20,30,40,50$, and $60 \mathrm{climbs} / \mathrm{min}$.

The results of the present study are confirmed by other authors, who also noted a beneficial influence of aerobic exercises for smoking cessation $[27,29]$. This influence appears to be particularly significant in women, as the exercises improve the women's physical fitness, the frame of mind and comfort, as well as counteracting withdrawal effects.

\section{Genetic analysis}

An interesting mouse model study on genetic influences on factors determining smoking cessation success in humans was published by Hall et al. [30]. In the present study we found that individuals with a long allele 7 (4-8 repeats, 48 base pairs) was no statistical significance to quit smoking more easily $(p=0.0645)$. It is an interesting observation in the context of Ebstein's conclusions on the association of the $D 4 D R$ gene with the personality trait of novelty seeking that allele 7 is present more often in individuals with the enhanced novelty seeking trait than in individuals without allele 7 [10]. The undertaken study of allele 7 in the $D 4 D R$ gene indicated its significant role in the process of smoking cessation in the group of young female students.

\section{Logistic regression model in smoking quitters}

One aspect of the present pilot study was seeking variables affecting smoking cessation. The 
analysis of data from the two groups of women using the single-factor logistic regression model revealed the statistically significant influence on smoking cessation of such factors as smoking intensity, D4DR gene (individuals with allele 7) and study group.

The results of the study showed that physical exercises in combination with concentration training, and genetic determinants have a positive impact on quitting smoking. The greatest impact was noted for variables that were most significant for the study, i.e. study group and allele. This confirms that the likelihood of smoking cessation in physically active individuals is much (three times) greater, and that individuals with allele 7 have two times greater chances of smoking cessation than others. On the other hand, the present study also revealed that the longer the nicotine dependence, and the lower number of smoked cigarettes, the greater is the likelihood of quitting smoking.

The study revealed differences between two groups of examined women in terms of smoking intensity and years of smoking and smoking cessation chances. However, the logistic regression model indicated significant smoking cessation with regard to smoking intensity. In the analysis of characteristics of both groups of women the basic model of regression included variables explaining a similar area of study. The analysis of models for women in two different groups revealed which factors (variables) affect smoking cessation, and to what extent. It was revealed that particularly significant for smoking cessation were smoking intensity, group and gene. However, two variables - group $(O R=3.17)$ and gene $(O R=2.35)$ showed the highest predictability in the model of smoking cessation in women. This is an indication of a far greater contribution of aerobic training and genetic determinants to smoking cessation. Among young female smokers the established model of variables can be used as encouragement for joining anti-smoking programs using concentration and aerobic training. It can be assumed that women who smoked sporadically (from 3 to 5 cigarettes a day) attempt to quit the habit by consciously participating in physical exercises. Greater participation in physical training reduces smoking as well as increasing the chances of complete smoking cessation [31, 32].

\section{Acknowledgments}

Special thanks should be given to Mrs Magdalena Lewandowska (Poland) for her professional statistical analysis.

\section{Conflict of interest}

The authors declare no conflict of interest.

\section{References}

1. Ebbert JO, Hughes JR, West RJ, et al. Effect of varenicline on smoking cessation through smoking reduction: a randomized clinical trial. JAMA 2015; 313: 687-94.

2. Bowker K, Campbell KA, Coleman T, Lewis S, Naughton F, Cooper S. Understanding pregnant smokers' adherence to nicotine replacement therapy during a quit attempt: a qualitative study. Nicotine Tob Res 2016; 18: 906-12.

3. Patnode CD, Henderson JT, Thompson JH, Senger CA, Fortmann SP, Whitlock EP. Behavioral counseling and pharmacotherapy interventions for tobacco cessation in adults, including pregnant women: a review of reviews for the U.S. preventive services task force [Internet]. Rockville (MD): Agency for Healthcare Research and Quality (US); 2015. Report No.: 14-05200-EF-1. U.S. Preventive services task force evidence syntheses, formerly systematic evidence reviews.

4. Darlow S, Lobel M. Smoking behaviour and motivational flexibility in light and heavy smokers. Addict Behav 2012; 37: 668-73.

5. Piłaciński S, Zozulińska-Ziółkiewicz DA. Influence of lifestyle on the course of type 1 diabetes mellitus. Arch Med Sci 2014; 10: 124-34.

6. Dudzińska D, Boncler M, Watala C. The cardioprotective power of leaves. Arch Med Sci 2015; 11: 819-39.

7. Torchalla I, Okoli CTC, Hemsing N, Greaves L. Gender differences in smoking behaviour and cessation. J Smok Cessat 2011; 6: 9-16.

8. Marcus BH, Albrecht AE, Niaura RS, Abrams DB, Thompson PD. Usefulness of physical exercise for maintaining smoking cessation in women. Am J Cardiol 1991; 68: 406-7.

9. Ussher MH, Taylor AH, West R, McEwen A. Does exercise aid smoking cessation? A systematic review. Addiction 2000; 95: 199-208.

10. Kotler M, Cohen H, Segman R, et al. Excess dopamine D4 receptor (D4DR) exon III seven repeat allele in opioid-dependent subjects. Mol Psychiatr 1997; 2: 251-4.

11. Benjamin J, Ebstein RP, Lesch KP. Genes for personality traits: implications for psychopathology. Int J Neuropsychopharmacol 1998; 1: 153-68.

12. Schefke T, Gronek P. Improving attentional processes in sport: defining attention, attentional skills and attentional types (Part I). Stud Phys Cult Tourism 2010; 17: 295-9.

13. Schefke T, Gronek P. Improving attentional processes in sport: sport specific issues during effective playing time (Part II). Stud Phys Cult Tourism 2011; 18: 9-16.

14. Schefke T, Gronek P. Improving attentional processes in sport: classifications of exercises and principles of development of attentional skills (Part III). Stud Phys Cult Tourism 2011; 18: 103-24.

15. Miller WC, Wallace JP, Eggert KE. Predicting max HR and the $\mathrm{HR}-\mathrm{VO}_{2}$ relationship for exercise prescription in obesity. Med Sci Sports Exerc 1993; 25: 1077-81.

16. Fiore MC, Bailey WC, Cohen SJ, et al. Treating tobacco use independence. Clinical practice guideline. Publications Clearinghouse, Rockville 2000.

17. Grable JC, Ternullo S. Smoking cessation from office to bedside. Postgrad Med 2003; 114: 45-54.

18. Hughes JR. Reduced smoking: an introduction and review of the evidence. Addiction 2000; 95 (Suppl 1): S3-7.

19. Lancaster T, Stead L, Silagy C, Sowden A. Regular review: Effectiveness of interventions to help people stop smoking: findings from the Cochrane Library. Br Med J 2000; 321: 355-8.

20. Pirie PL, Murray DM, Luepker RV. Gender differences in cigarette smoking and quitting in a cohort of young adults. Am J Public Health 1991; 81: 324-7. 
21. Grogan S, Fry G, Gough B, Conner M. Smoking to stay thin or giving up to save face? Young men and women talk about appearance concerns and smoking. $\mathrm{Br}$ J Health Psychol 2009; 14: 175-86.

22. Grogan S, Hartley L, Conner M, Fry G, Gough B. Appearance concerns and smoking in young men and women: going beyond weight control. Drug Educ Prev Polic 2010; 17: 261-9.

23. Jessen A, Toubro S, Astrup A. Effect of chewing gum containing nicotine and caffeine on energy expenditure and substrate utilization in men. Am J Clin Nutr 2003; 77: 1442-7.

24. Nicklas B, Tomoyasu N, Muir J. Effects of cigarette smoking and its cessation on body weight and plasma leptin levels. Metabolism 1999; 48: 804-8.

25. Meyers AW, Klesges RC, Winders SE, et al. Are weight concerns predictive of smoking cessation? A prospective analysis. J Consult Clin Psychol 1997; 65: 448-52.

26. Ciccolo JT, Dunsiger SI, Williams DM, et al. Resistance training as an aid to standard smoking cessation treatment: a pilot study. Nicotine Tob Res 2011; 13: 756-60.

27. Williams DM, Ussher M, Dunsiger S, et al. Overcoming limitations in previous research on exercise as a smoking cessation treatment: rationale and design of the "Quit for Health" trial. Contemp Clin Trials 2014; 37: 33-42.

28. Gimenez M, Saavedra P, Gimenez M, et al. Two-step stool aerobic training for smokers. Am J Phys Med Rehab 2014; 93: 586-94.

29. Smits JA, Zvolensky MJ, Rosenfield D, et al. The efficacy of vigorous-intensity exercise as an aid to smoking cessation in adults with elevated anxiety sensitivity: study protocol for a randomized controlled trial. Trials 2012; 13: 207.

30. Hall FS, Markou A, Levin ED, Uhl GR. Mouse models for studying genetic influences on factors determining smoking cessation success in humans. Ann NY Acad Sci 2012; 1248: 39-70.

31. Broman-Fulks JJ, Berman ME, Rabian BA, Webster MJ. Effects of aerobic exercise on anxiety sensitivity. Behav Res Ther 2004; 42: 125-36.

32. Smits JA, Berry AC, Rosenfield D, et al. Reducing anxiety sensitivity with exercise. Depress Anxiety 2008; 25 : 689-99. 